\title{
INFLAMMATORY DISEASE IN THE EYE CAUSED BY GOUT
}

BY

\author{
D. J. WOOD
}

CAPE TOWN

IN this twentieth century now one third gone we are apt to forget what a large part was played or was supposed to be played by gout in the days of our great-grandfathers.

Even the older ophthalmic surgeons are, I think, in danger of overlooking gout as a cause or a complication in the production of certain eye diseases, the more so because they are not common. No doubt it is true that many of the ailments formerly ascribed to gout are known now to be due to quite other conditions, but nevertheless in our more limited experience, since gout has become less frequent than it was, we find from time to time cases of ocular disease which correspond exactly with those carefully described by Jonathan Hutchinson, and by him correctly attributed to gout.

With four such cases I have had to deal during the last fifteen years. In them no other gross or manifest evidence of gout existed, and therefore other and more modern aetiologies had been sought, and paid for, without success.

The cases were all more or less similar, and as they are not common and little has been written about them of recent years it may be worth while to give the records in detail.

In all the first sign of trouble was an attack of episcleritis fugax, and this continued to form part of the syndrome through the course of the trouble.

My first case occurred in 1920, when a lady sixty years old came to me complaining of a recent pain in her left eye, which had come on suddenly, and was associated with prominence of the eyeball. The attack had occurred on a Saturday night, and when I saw her on the following Monday it had largely disappeared. There was still conjunctival redness, the eyelids were swollen, and the eye a little proptosed. There was no discharge from the eye, and no implication of the cornea or iris. Pain had ceased but had been severe, and felt all through the orbit. She had coronary cataract, rather extensive, and even the correction of her myopia gave her only 6/24ths of vision.

She had lived in India for some time where her husband's position had made hospitality and good living part of his duties, and subsequently she at least had not fallen behind her former habits. I could not come to a diagnosis, the nearest approach to 
my mind being that it had been produced by some external irritant, possibly a pollen, though the dryness of the eye was against this. I did not realise the condition as a danger signal, and owing to my compulsory indefiniteness I did not see her for a long time, as she went to England when her attacks recurred. There she was told she had iritis and various examinations were made to find a septic cause. Curiously her very bad teeth seemed not to have been considered as requiring attention. Examination of the eye when she came back shewed that she had a couple of small iritic adhesions which did not tally with her tale of sixteen severe attacks during the interval since I saw her first. The attacks were always the same. Severe burning pain in the eye; with redness, and more or less protusion of the eyeball. It came on quickly, and lasted as a rule between one and three days during which time she could scarcely open her swollen eyelids, or use her eye in any way. After each attack the eye cleared up rapidly and became as good or nearly as good as formerly. I got her own medical attendant to examine her carefully on the supposition that the attacks were episcleritis periodica fugax, but I had never seen her in one except when it had nearly passed off.

He found very little amiss. She had a subnormal temperature but no other evidence of thyroid insufficiency. There was some arteriosclerosis, and a good deal of increase over normal blood pressure. Her teeth were very bad. These were dealt with radically, and she was put on very light diet with almost nothing in the way of alcohol. For local atacks she was to use atropine and dionine and hot bathing. For a time her attacks lessened. Recurrences induced her however to try elsewhere and she was again treated for iritis and was made rather ill by a protein shock. In the end however I was asked to come to her own home and I saw her for the first time during a bad attack. Her eye was greatly proptosed, the eyelids swollen and red, there was conjunctival redness and chemosis and the iris looked dull with a very small pupil. She could not open the eye, and movement of the other eye gave much pain. She had had no sleep during the night. It was clear that she had episcleritis fugax with other features added probably tenonitis and perhaps iritis. Like former attacks this one passed off in about three days and when I was able to see her in my consulting room there was very. little left amiss. Each attack did however leave her a bit worse as regards vision, and she became unable to read. More pupillary adhesions formed, more pigment was deposited on the lens and there were vitreous opacities. Her death from cardiac failure and hypostatic pneumonia ended further observations.

Case 2.-A gentleman aged about 66 came to see me at my residence in 1932 on account of swelling and redness of his left 
upper eyelid. The sclerotic was also red, and the conjunctiva oedematous.

His idea was that he had been bitten by a mosquito, and the appearances were by no means unlike such a cause. When however he returned with the same thing in the same eye a few months later I thought that episcleritis periodica fugax was a more likely explanation. Treatment with dionin seemed to end the trouble and $\%$ I did not then realise as I do now that it might be the precursor of much worse things. A few similar attacks occurred in 1933 but in 1934 he got an attack which during my absence was diagnosed as severe iritis. When I returned and saw him it was clear that he had had iritis, but the only evidence left was a single small iritic adhesion in his right eye. He had been told also that he had pernicious anaemia the diagnosis being based on measurement of his blood cells. I got him carefully examined and it was found that he had a megalocytic anaemia not however of the pernicious $\subseteq$ type. He had been losing weight, and occasionally there was a trace of blood in his stools, but with no evidence of any malignant disease of his intestinal tract. He had lived well, being a large meat eater, and he had been generous in his allowance of rather heavy wines.

His diet was restricted, and for a long time he was definitel $8 \overrightarrow{0}$ better in health, but before very long he got a second severe inflammatory attack in his right eye. The conjunctiva wa을 oedematous, the iris very dull, and the aqueous extremely hazy?

The uric acid content of his blood during the attack was 4.6 milligrammes per 100 c.c. while in the succeeding interval it was only 3.5 milligrammes. Another symptom which he had had for long was a dry itchy skin which was said to be due to " metabolic disturbances " by a dermatologist.

It was curious that in spite of the alarming looking state of his eye he had hardly any pain, merely discomfort, and indeed throughout all his attacks which went on during over two years he rarely had recourse even to aspirin, though when his eye was uncomfortable during the night this gave him relief and sleep. The attacks were not confined to his right eye but the damage done to it was the greater, and iritic adhesions gradually made it impossible to get more than partial dilation of this pupil. During 9 an attack his aqueous would be filled with a fibrinous coagulum which vanished quickly with the subsidence of the acute stage. The dieting brought for a time an increase in weight and an im- . provement in his anaemia, but this was not permanent and he got recurring inflammatory attacks in one or other eye. They lasted about a week and were not associated with any proptosis. In March, 1935, his vision had been 6/12 in the right eve, and 6/9 in the left, but by October it was much less in the right, and if 
the left eye was inflamed he could not read. In this same month he developed two new conditions, oedema of his eyelids, round the eyes, and back towards his ears, and in his arms, and in his eye attacks he began to get precipitates on the back of his corneae which till then had been absent. Like the rest of his eye inflammation these precipitates disappeared with unusual rapidity when the attack subsided. He continued to grow thinner and for a week went on a Bulgarian milk diet. This did not however help, and he went to another physician for an opinion. It was found that in addition to arterio-sclerosis and enlarged heart he had an extensive venous thrombo-angiitis. His anaemia was severe and a more generous diet had to be allowed.

This brought his blood cells to about half normal and his haemoglobin to 46 per cent. I had tried to get him to go to England for an opinion by someone expert in gouty conditions but he refused. In the end the opinion by his second physician alarmed him, and he decided to go, but to Germany. In this however his heart failure intervened. He became ill soon after his arrival, and died of cerebral haemorrhage.

In contrast to the former case he had no pain, and no proptosis while both these were present in the other. This seemed to associate the pain with Tenonitis, agreeing therefore with observations by Hutchinson that pain is not severe in gouty iritis without other complications. He emphasised the fact that while there might not be much pain, gouty iritis may be insidious and destructive. I think that there is little doubt that had my patient lived long enough he would have become practically blind.

Case 3.-A lady then of forty-six years came to consult me in 1932. Her story was that she had had three attacks of pain in her left eye which had been diagnosed as iritis. She had also had a marginal ulcer of which one could see a faint scar.

I found a single round ball of pigment in the pupillary area, and three specks of pigment lower down where iritic adhesions had probably given way. Her story of very severe pain seemed out of proportion to what one could see amiss, and I thought it might have been an actual fifth nerve neuralgia.

One could see far back in the vitreous some rounded opacities, but her vision was $6 / 5$. She was presumably not satisfied, and I did not hear of her again till April, 1934, when at a University faculty meeting two of the staff independently spoke to me about the case. The description was so clear that one felt nothing except episcleritis periodica fugax with possible complications could explain the attacks.

She was brought back to me and gave a history of much having been done to her. Her teeth had been extracted, her tonsils had been removed, and she had had a gynaecological operation. 
She had been given atophan by her own medical attendant, $\frac{0}{.}$ and it was suggested that her liver had thereby suffered. She had $\Rightarrow$ in fact had much done both medically and surgically to discover a cause for her frequent attacks of severe ocular pain, and was definitely neurotic in consequence.

Examination shewed little advance since her former visit except that there were now three small synechiae where the former pigment spots were. In the vitreous however were numbers of rather large rounded opacities, larger than the ordinary dust seen in irido cyclitis, and very sharply defined. I have seen such before but have not been able to explain their nature.

The attacks of pain had become very frequent, so that she was hardly ever free for more than a week, and yet her iris was bright $\tilde{O}$ and almost free from adhesions. I decided that it was probably gouty and in her next attack her blood was taken and shewed 4.14 milligrams of uric acid per 100 c.c. while between attacks it was 2.3 milligrams. She was put on a diet which she probably adhered to, but she did not take kindly to any drugs. Colchicum upset 0 her digestion, atophan made her itch and I do not know how far she kept on with any medical treatment. In the height of an attack there was eyelid oedema, proptosis, dislike of moving the eyes, iris dullness and great scleral redness which lasted longer than the iris change.

As the patient was confined to bed it was not possible to gef a satisfactory examination during the worst stage. In Aprif 1934, I did get her to come to my consulting rooms just after an acute attack. My attention was drawn to some faint blurs on her cornea which were new, and the slit-lamp shewed them to be acicular crystals in sheaves, narrowed in the middle. They were less than one millimetre in length. Descemet's membrane was also covered with stellate points and dots, whether crystalline or not was uncertain. There was a lot of vitreous haze, and she admitted seeing 6/60 only. I could however see large fundus vessels. One had to admit that the patient was not improving, and I was not surprised to hear that she wished to go to England. I went to the trouble of writing out a long report for a well-known London ophthalmologist, and sent it to him, giving the patient an introductory note. Unfortunately she was diverted elsewhere, so that my record was not available for the gentlemen to whom she went. He agreed however that Tenonitis was present. She came back without any report on her general condition which was what I specially desired, and in place of improvement became gradually much worse.

Morphia and hyoscine had to be given whenever the attacks occurred, and vision was getting progressively worse. There was hardly any fundus reflex and vision of a lighted hand was good 
only on the temporal side. In spite of all this however as soon as the pain ceased the iris would become bright again and the original synechiae were all that existed. Finally she agreed to part with the eye, and it was excised under sodium evipan, the socket being very freely washed out with warm alkaline solution. No further trouble has occurred in the socket though of course much of Tenon's capsule was left. She has since had slight scleral redness in her good eye but nothing in the way of episcleritis periodica fugax.

My fourth case has been too satisfactory to be instructive. A man about fifty years of age came to me with a history of repeated acute attacks of pain and redness with protrusion of his right eye. He had seen two ophthalmic surgeons, and he gave me a long list of physicians to whom he had gone. The attacks had been going on for more than a year, and he was just over one when he came to me. There was however enough for a diagnosis to be made. He had been a big meat eater and drank lots of beer. He undertook to change his habits, and I have seen him no more though he has assured me on the telephone that he will come back at once if he gets more trouble. He has been free for nine months from all attacks. Here again his pain seems associated with proptosis, and inferentially with Tenonitis.

Taking the four cases one found that all began with a sudden scleral redness which usually came on during the night, and was not painful, though Hutchinson's term "Hot Eye" described the sensations well enough. Episcleritis periodica fugax is also a good description. It is not a very painful condition when uncomplicated, and till I saw the first of the cases here recorded it had not struck me as being serious, though I admit that few have come my way. Cases have been recorded as occurring in several members of the same family. This can be understood if all inherited or acquired a gouty diathesis.

In the three first cases iritis looked much more severe than would be guessed if one judged by the small residual damage, and this conforms to the appearances seen in sections of the iris. The very sudden onset, relatively short duration, and rapid cessation of pain, are all in contrast to what obtains in the majority of cases of iritis, and suggests that the irritant is not bacterial but possibly chemical. The appearance of severe irido-cyclitis is exaggerated by the lid oedema, but the amount of tenderness to pressure was very slight. Even where there had been exudate into the anterior chamber, and, in my second case, deposits on the endothelium, these cleared up remarkably quickly when the acute stage ended. Vitreous opacities were present in all, and in two were rather large rounded atoms. One was tempted to say they might be urates, but a chemical test gave no support to this. The three cases 
which complained of pain all had proptosis, and in two any movement of the eyes made this worse, indications I think of Tenonitis. The corneal crystals were new to me and could not have been seen in pre-slit-lamp days. Mr. Doggart's interesting paper appeared in this Journal just after I saw them, and from it I learned that Weve and Scheffels had seen similar crystals in what they called keratitis urica.

Since it is now possible to get accurate estimates of the uric acid content of the blood we are in a better position to diagnose gout. It would appear to be reliable not so much when there is a mere increase, as when the increase corresponds with the attack of inflammation. South Africa is however not a gouty country, and few medical men have much first-hand experience of it. As the country makes and uses large amounts of rather heavy and often acid wines, the absence of gout may perhaps be due in some way to the absence of the hereditary element.

Treatment to be effective must I think be early, drastic, and suggested with confidence. This point is brought out in Case 4 by its success, and by the comparative failure in the other three: The patient must be left in no doubt as to what is amiss, and he must be made to understand that it is due to a condition which may be hereditary, but which is almost certainly of longer stand ing than his complaints. Unless he is convinced he will not take kindly to restrictions of diet, and stoppage of alcohol. Furthes he must be prepared to put up with discomforts produced by medicines, whether colchicum or cincophen. I do not know of any local treatment save dionine, and, when there is iris involvement, atropine. Possibly hyoscine will have to be substituted in many cases owing to the chance of producing atropine irritation. Heat in any form will give some relief. As to pathogenesis we are still waiting for knowledge.

I believe that it is admitted now that uric acid per se is not the cause of gouty inflammation in the tissues. A high degree of uric acid content in the blood may be however the first evidence of an abnormality in nuclein katabolism. The excessive amount mav be due either to this or to large quantities of nucleins and purin bodies in the diet. The former would supply the hereditary element; the latter the acquired. As a result of a raised kidney threshold for uric acid a uricaemia results. In the tissues the uric acid anions meet with sodium cations forming sodium urate, some of which is excreted and some deposited locally. The loss of sodium cations may however upset the ionic balance both in the cells and the surrounding fluid, and in consequence other cations may become toxic and produce a pathological or destructive action. If this be so, the tissues containing much sodium would be most affected, and it is interesting to note that in the eye those 
are the sclerotic, the cornea, and the choroid. The avascularity of the cornea would however save it from serious damage. In the cases described the sclerotic was always the first to suffer, and in some cases it never goes further.

There is a suggestion that the attacks recur as a result of foregoing attacks. Since the eye of Case 3 has been removed, there has been no trouble in the socket, or anywhere else save slight and apparently unimportant redness in the remaining eye, entirely different in character from the former condition.

Pathological examination of the eye removed from Case 3 . Fixation was by Bouin's fluid. After removal from this the eye was washed with water, and in doing so a rough patch was observed near the posterior pole and scrapings from this showed numerous small crystals lying for the most part along the remains of a blood vessel. Unfortunately the specimen was mounted in balsam in the expectation that other scrapings would shew the same, and could be used for a micro-chemical test. This was not however the case, and no other scrapings gave any uric acid reaction when treated with Benedict's uric acid reagent by a friend doing biochemistry. The fact that no other area showed crystals, plus the fact that similar crystals were found in a neighbouring area in some sections seems to negative the possibility that they were artefacts.

In order not to disturb the lens, the eye was cut in half by a coronal incision. In doing so the vitreous was found to be very unusually tough. The anterior half remained in position, the posterior fell out. This latter part was sectioned at once, and tested for uric acid but gave no reaction. It was composed of fine fibrils of collagenous material containing practically no cells. It was evident however that very little actual vitreous was left, or its substance had been completely pervaded by collagenous material which had formed fine fibrillae.

The examination of the rest of the eye was made after embedding in celloidin, and various changes were found which were in accord with the clinical observations.

The cornea was of somewhat loose texture at its margins, but there was no cell infiltration. The abnormality may have been an artefract. Although the aqueous had been clear clinically it had contained much albuminous material, as almost the whole of the anterior chamber was filled with the same fine coagulum as had been seen in the vitreous. It was most dense near the cornea, and shrinkage here had produced a line of rounded spaces next to the endothelium. No cells were present anywhere, in contrast to what is found in ordinary recurrent iritis.

On the outer surface of the globe, from where the conjunctiva begins, there was a great thickening of the sclerotic which was as nearly as may be double its normal measurement. Part of this 
is due to an episcleral change, the tissue being full of new blood vessels and cells. This is seen in the photograph Fig. 1.

Deeper than this there is also much vascularity, but the more superficial parts of the sclera proper are full of:lymphocytes and plasma cells. There are also numerous spaces between the fibres which contain new collagenous material in fine fibrillae.

Fig. 2 shows the external half of the sclerotic, while Fig. 3 is of the internal portion.

In this latter the changes are even greater. The scleral fibres are spaced out by collagenous exudate, staining with eosin or acid fuchsin, and shewing fine fibrillae. There is however no necrotic change anywhere such as one sees in tuberculous disease. As one passes towards the choroid the quantity of plasma cells and lymphocytes increases so that the normal boundaries of sclera and choroid are lost, save for traces of the lamina supra-choroidea, and the choroid in front is represented only by scattered pigment. The retina begins with a much swollen ora serrata, passing into cystic spaces, and further back is detached, the subretinal space being filled with fine fibrillary exudate with large oval cells.

The ciliary body is increased in size as a result of the separation of its fibres by fibrillary exudate, with clumps of lymphocytes, and in all sections of the iris a large collection of lymphocytes is present near the root.

All through the iris may be seen inflammatory cells, but no in numbers correponding to the very numerous attacks of in flammation. This discrepancy is most marked near the tip of the iris, where the arterioles and venules pass into each other, and where in consequence there is to be found in cases of iritis a large number of cells. In this case they are absent (Fig. 4).

There seems to be no destruction of uveal tissue, and hardly any evidence of its adhesion to the lens capsule. This agrees with the scanty synechiae which were seen intra vitam.

The whole space round about the lens is full of the same fine fibrillary coagulum seen in the aqueous and vitreous.

The retina shews signs of oedema in the loss of regularity of the layers, but there is no cellular invasion or destruction till one reaches the membrana limitans externa.

Beyond this however there is a striking change in the complete destruction of the bacillary layer, except over that part of the nasal periphery, which accounts for the loss of light perception except far out in the temporal field (Figs. 5 and 6 ).

Immediately outside the membrana externa is a line of dèbris which hardly stains. This, with contraction spaces, is all that is left of the rods and cones. The hexagonal pigment is somewhat lacking in its acicular pigment, as judged by the ease with which 


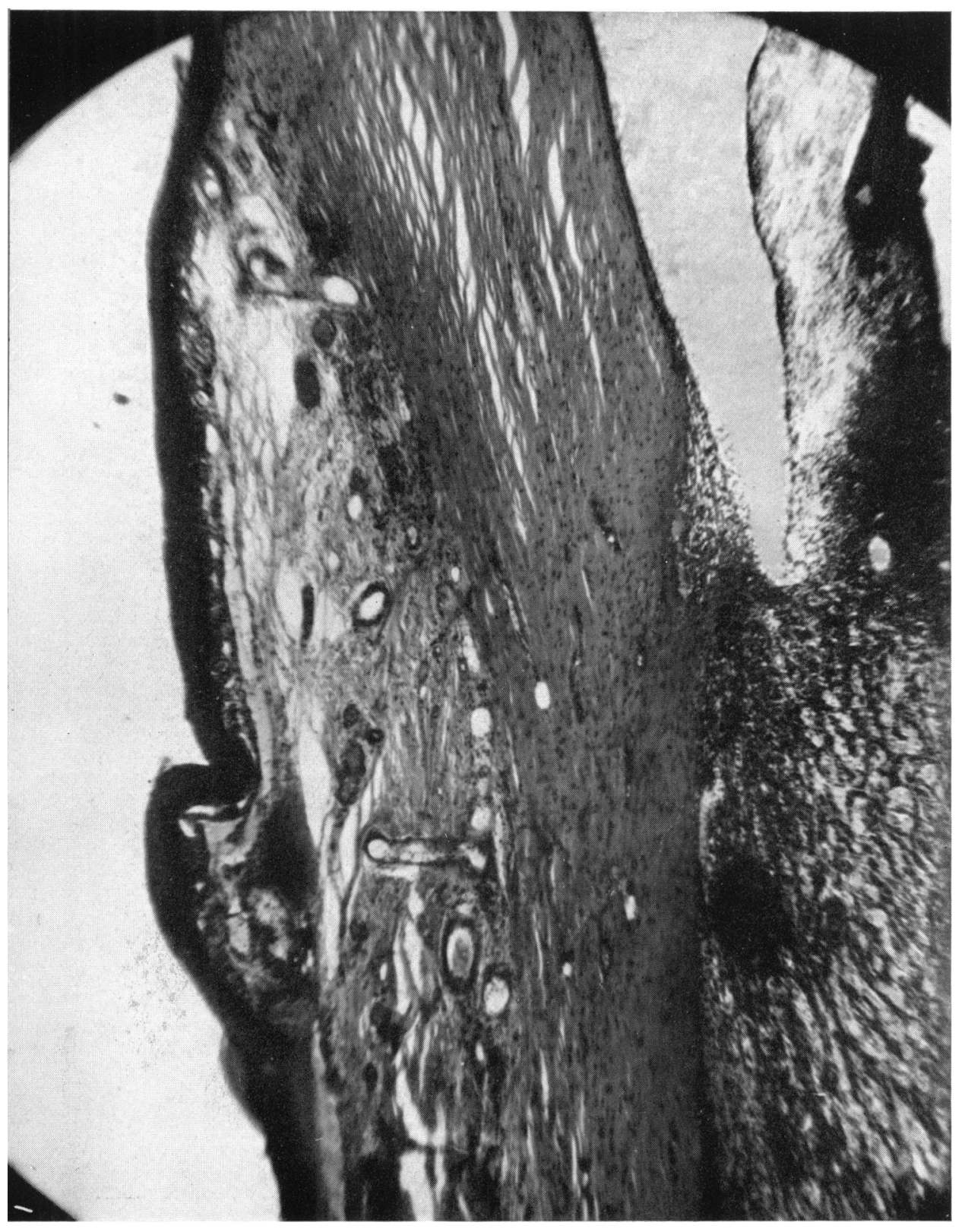

隔 م. - O잉 范三

范 范总

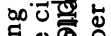
.

- 몽고옹

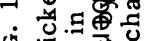

포원

ज्ञ

头

ख़े

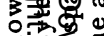
의 온

的素 म ह छे 도웜

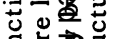
至表五 喝 氖骂专 윤도용 要 1 용. 蝶 ○े눈

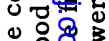
드용요

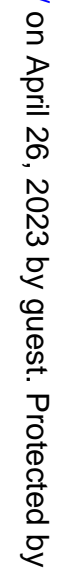




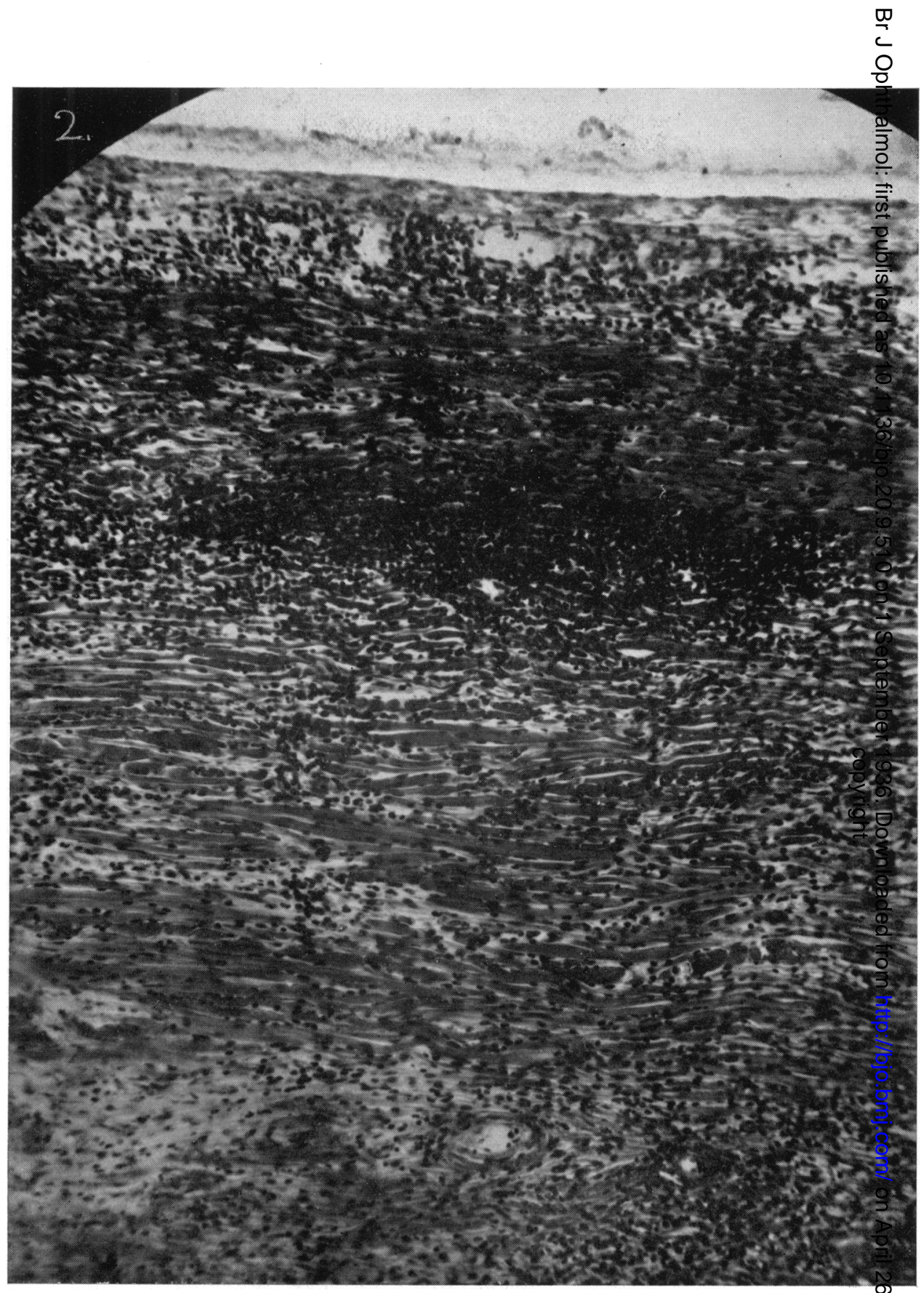

FIG. 2.

ก

The outer part of the sclerotic just behind the ciliary body. Its great thickening is due to separation of the fibres by cells and collagenous material. A clump of lymphocytes can be seen. 


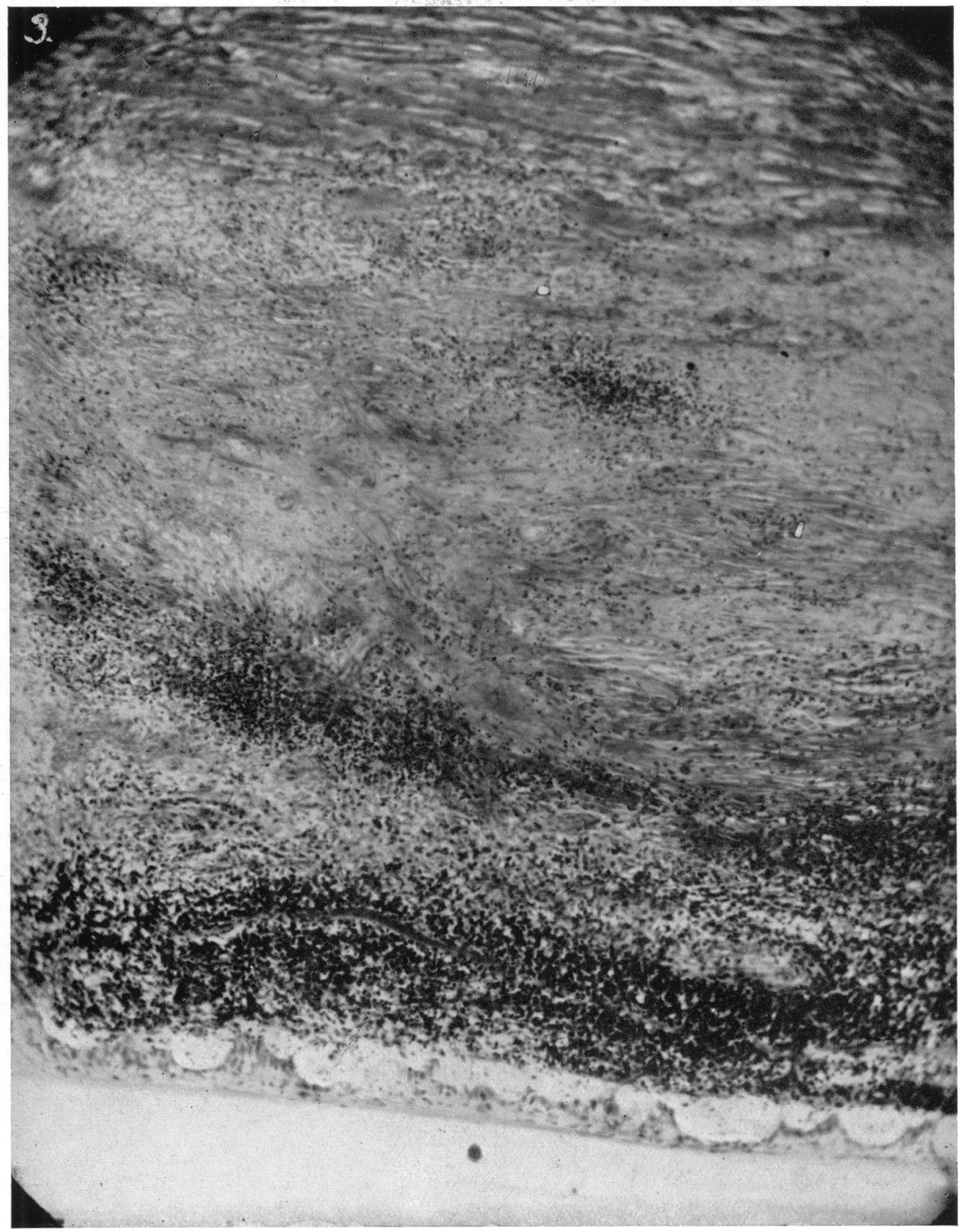




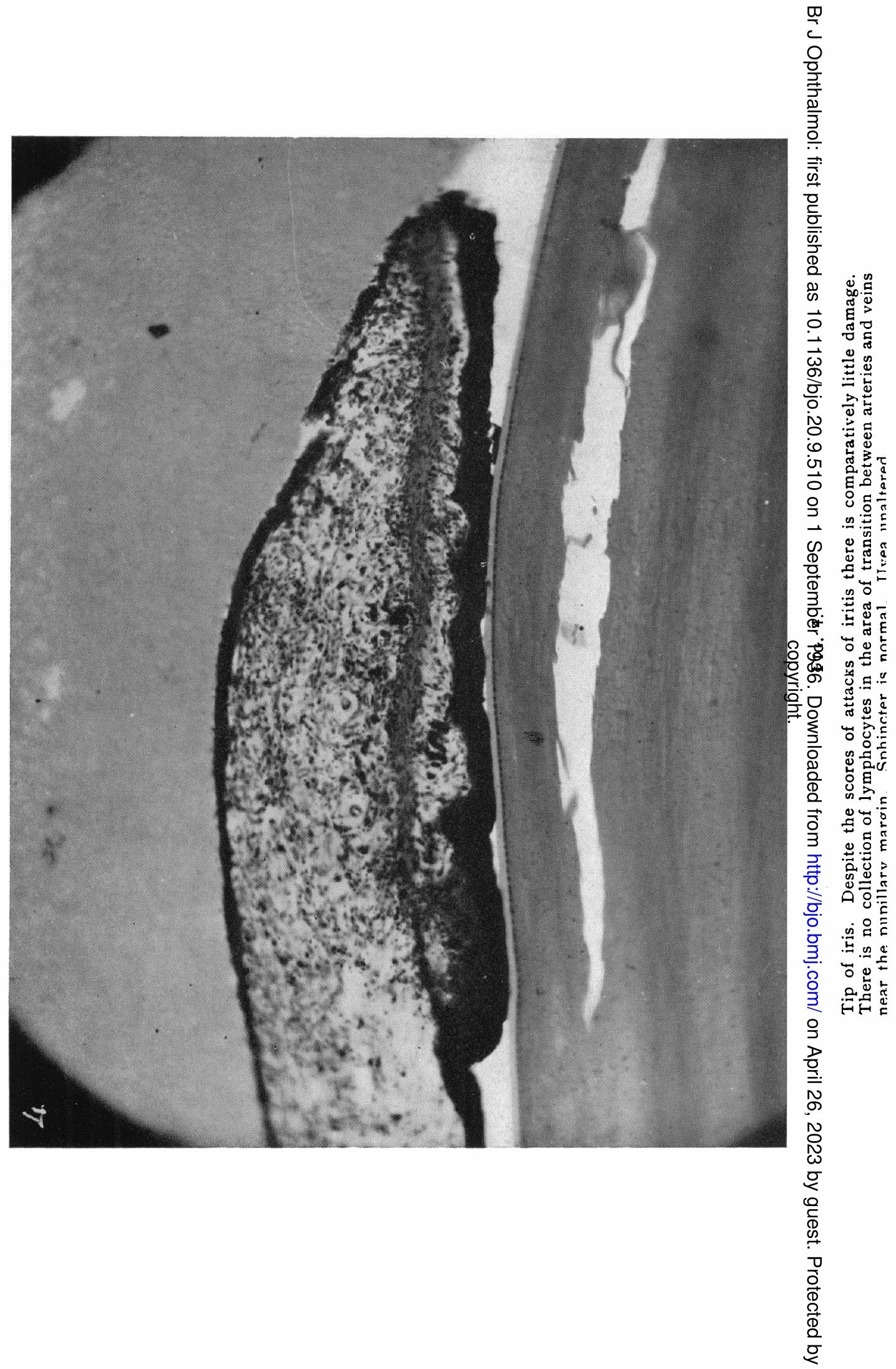




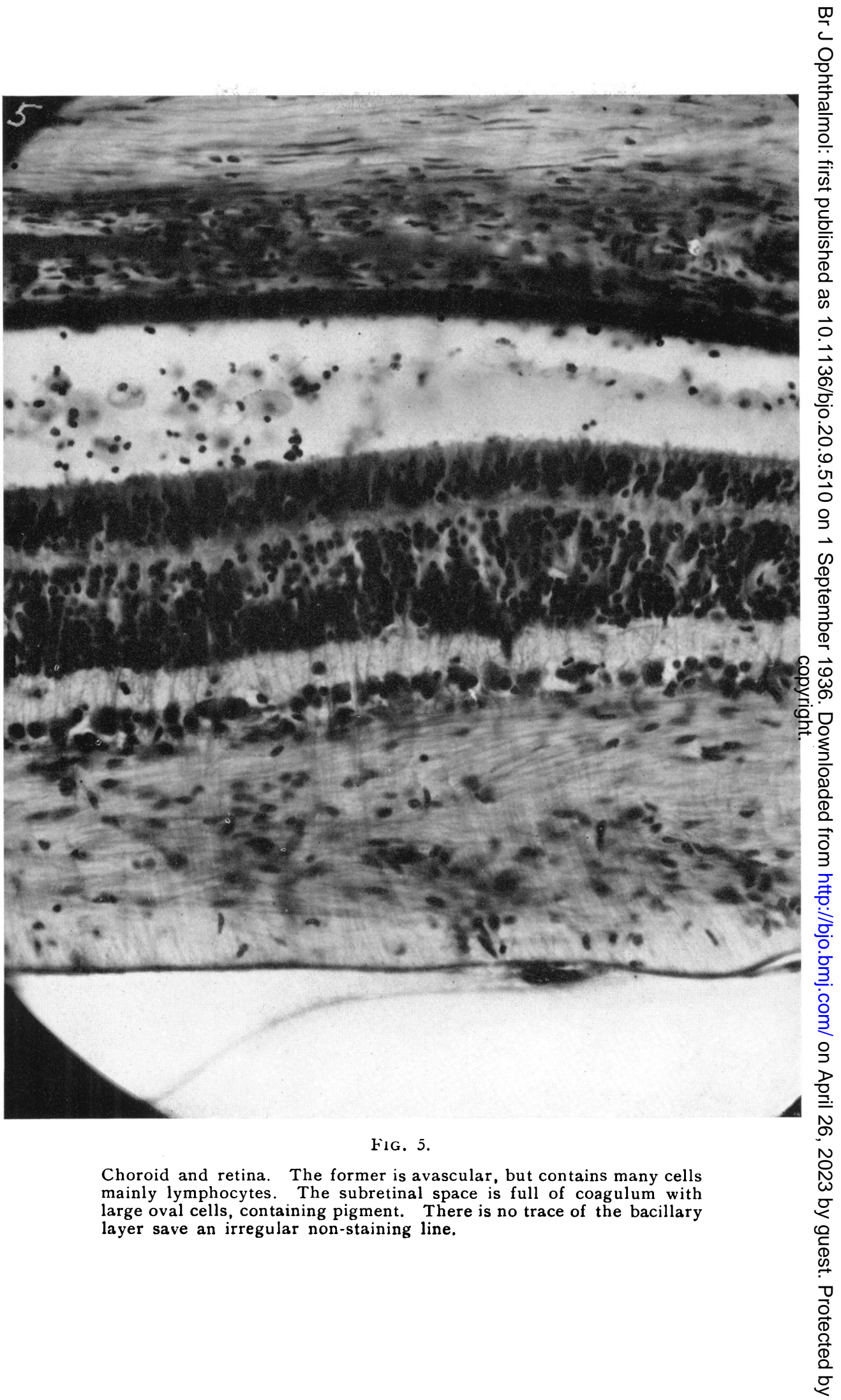




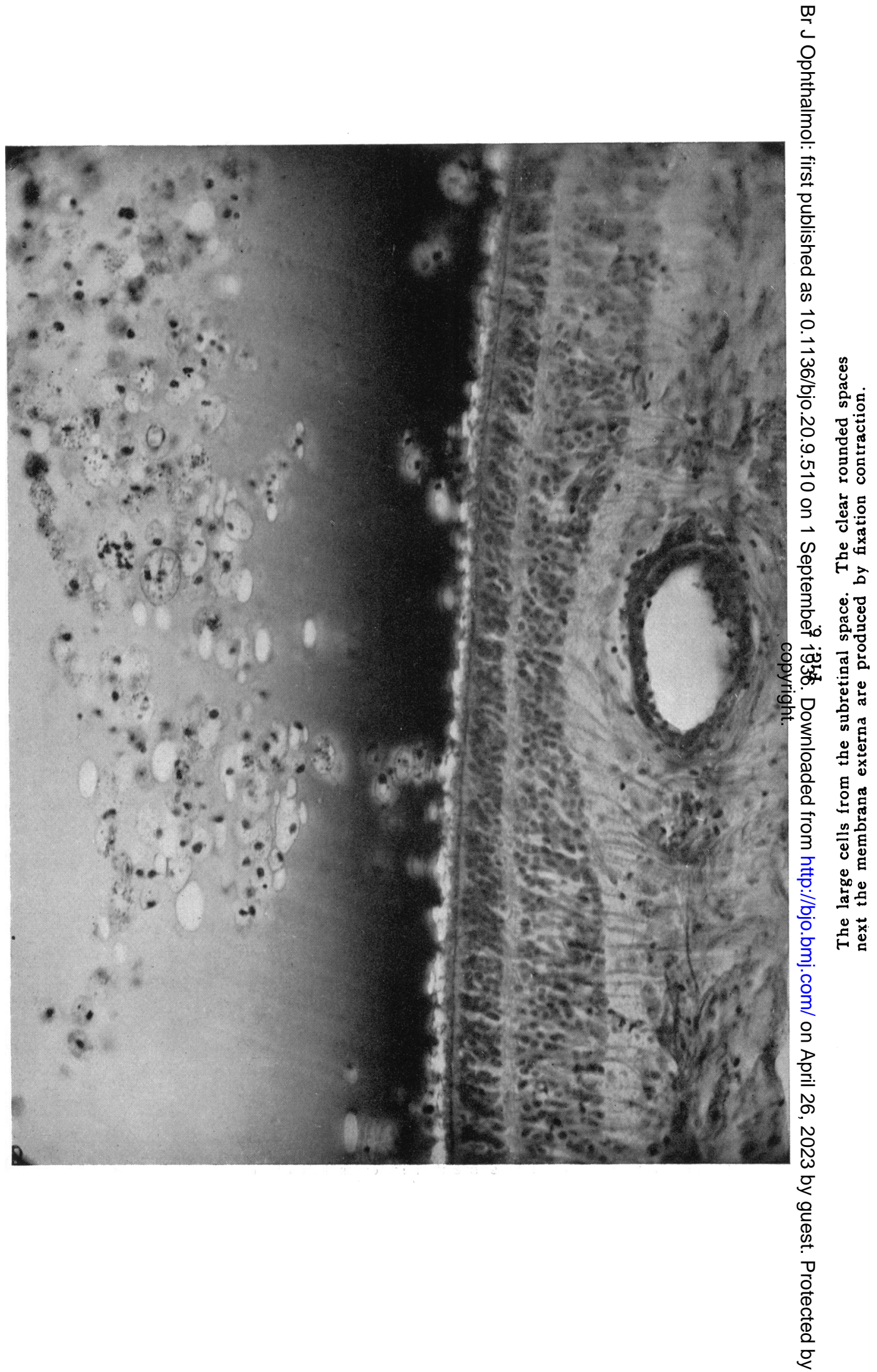




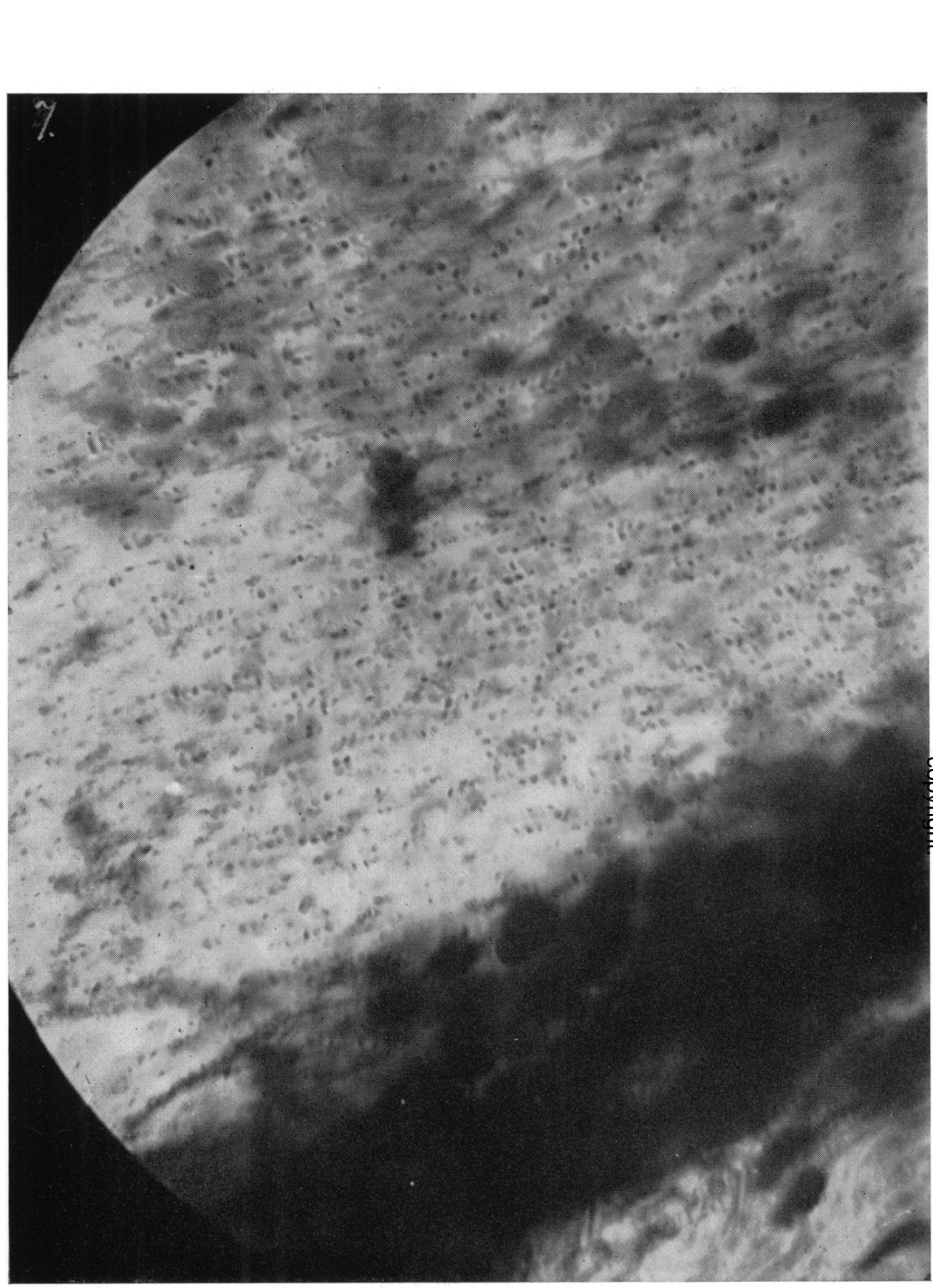


its nuclei are seen. In the coagulum in front are numbers of large oval cells which contain pigment of the acicular type. These cells are from ten to as much a forty $\mu$ in their longest diameter, and possess a small irregular nucleus. Their outline is very clear and sharp as indicated in the photographs. I suggested in the July, 1935, issue of this Journal that one of the functions of the membrana limitans externa was to form, with the lamina vitrea, a lymph space for the nutrition of the rods and cones lying in it. In this case these have been destroyed, while outside the retina is scarcely altered. The suggestion of some irritant in the lymph seems natural, even allowing for the fact that the rods and cones are easily damaged.

The choroid is avascular and full of cells. One cannot make out any chorio-capillaris. In the anterior part are lymphocyte collections but nowhere large. The optic nerve appears to be free from inflammatory change.

On the posterior surface of the sclerotic there are, at one or two spots, myriads of tiny brown crystals. The brown tint is seen with a magnification of about 100 , but the individual crystals need a twelfth inch. 'They are about the size of average bacteria, but as they lie in different planes I have failed to get a sharp photograph of them. Fig. 7 gives an idea of their numbers and of their size compared with haemocytes. Again it was unlucky that the crystals were found in a mounted specimen so that chemical tests were not possible. The patient had had many attacks of what were in part Tenonitis, and it is not unreasonable to conclude that these crystals, and those seen once in the cornea, were urates.

It would seem that there has been a definite selective action by the tissue irritant, as the sclerotic, the choroid, and the bacillary layer of the retina have been seriously damaged, while the iris and to a less extent the ciliary body have escaped. The lens remained clear.

The proof that gout is the principal cause is partly negative, in that the pathological conditions do not resemble any others which I have seen. On the positive side are to be placed the fact that in 3 cases Tenonitis was present, and that episcleritis periodica fugax was the commencement in all the cases. In three cases the patient's diet and use of alcohol were such as would naturally produce a gouty condition, and in one the cessation of beer, and diminution of heavy meat diet put an end to the troubles. Besides these points we found that in the two where an examination was made the uric acid content in the blood was greatly increased during the acute attacks. 